\title{
Strategi Aktivitas Pedagang Terhadap Pencemaran Kanal yang Berlokasi di Kanal Panampu Pasar Terong Kota Makassar
}

\author{
Strategy of Trader Activities Against Pollution of Locating Channels in the Panampu Canal, \\ Terong Market, Makassar City
}

\author{
Regil Indri Rahayu' ${ }^{1}$, Rudi Latief ${ }^{1}$, Jufriadi ${ }^{1}$ \\ ${ }^{1}$ Program Studi Perencanaan Wilayah dan Kota, Fakultas Teknik, Universitas Bosowa \\ ${ }^{2}$ Program Studi Pascasarjana Perencanaan Wilayah dan Kota, Fakultas Teknik, Universitas Bosowa \\ Email : regilrhyu@gmail.com
}

\section{Artikel info}

\section{Artikel history:}

Diterima; 08-11-2020

Direvisi: 09-11-2020

Disetujui;13-11-2020

\begin{abstract}
Activities traders around the canal pannampu give effect to the pollution of the canal. The purpose of this study was to identify the activity of Terong market traders who cause pollution in the form of garbage on Channel Pannampu Terong Market. This study is located in the District Bontoala by focusing locations around the canal Pannampu Terong market located in the Village of Tompo Balang. This study uses variable environmental knowledge, knowledge of government policy, the application of technology knowledge, attitudes and intentions. The analytical approach used in this research is qualitative approach.
\end{abstract}

\begin{abstract}
Abstrak. Aktivitas pedagang di sekitar Kanal Panampu memberikan dampak terhadap pencemaran kanal. Adapun tujuan penelitian ini adalah untuk mengidentifikasi aktifitas pedagang Pasar Terong yang menyebabkan pencemaran berupa buangan sampah pada Kanal Panampu Pasar Terong. Penelitian ini berlokasi di Kecamatan Bontoala dengan berfokus lokasi di sekitar kanal Panampu pasar terong yang terletak di Kelurahan Tompo Balang. Penelitian ini menggunakan variabel pengetahuan lingkungan, pengetahuan kebijakan pemerintah, pengetahuan penerapan teknologi, sikap dan niat. Pendekatan analisis yang digunakan dalam penelitian ini yaitu pendekatan kualititatif.
\end{abstract}

\footnotetext{
Keywords:

Toll Road

Development;

Accessibility

Conditions;
}

Coresponden author:

Email : regilrhyu@gmail.com

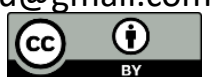

artikel dengan akses terbuka dibawah lisensi CC BY -4.0

\section{PENDAHULUAN}

Pedagang adalah orang yang melakukan perdagangan, memperjualbelikan barang yang tidak diproduksi sendiri, untuk memperoleh suatu keuntungan. (Sujatmiko, 2014:231).

Indonesia saat ini sedang diterpa isu penurunan kualitas lingkungan hidup yang semakin hari tampak nyata. Penurunan kualitas lingkungan hidup ini terjadi di daerah-daerah atau kota-kota yang sedang berkembang. Kegiatan pembangunan dengan berbagai aktivitas masyarakat mempunyai pengaruh langsung terhadap daya dukung lingkungan sehingga terjadi pergeseran keseimbangan lingkungan yang tidak proporsional, tidak efisien dan kurangnya tingkat kesadaran masyarakat dalam pengelolaan lingkungan hidup, sehingga menimbulkan permasalahan lingkungan hidup yang cukup serius.Menurut R.T.M Sutamihardja, Pencemaran lingkungan menurut R.T.M Sutamihardja adalah penambahan bermacam-macam bahan sebagai hasil dari aktivitas manusia ke lingkungan dan biasanya memberikan pengaruh yang berbahaya terhadap lingkungan itu.Kanal adalah saluran air buatan manusia yang dibuat untuk berbagai keperluan yang membantu kehidupan manusia. Kanal sudah dibuat manusia sejak ribuan tahun yang lalu. Kanal tertua ditemukan di Mesopotamia, sekitar tahun 4000 SM. Walaupun bentuk kanal hampir tidak berubah, teknologi pembangunan kanal makin berkembang. 
Berdasarkan kondisi eksisting, kebersihan kanal di Kota Makassar sangat memprihatinkan. Hampir seluruh permukaan kanal tertutup dengan sampah plastik maupun tumbuhan liar seperti eceng gondok. Dari sekitar $30 \mathrm{~km}$ panjang delapan ruas kanal yang ada di Makassar, tak satupun bebas dari sampah. Seperti Kanal Sinrijala, Panampu, dan Jongaya yang sudah menjadi tempat pembuangan sampah sebagian masyarakat yang tinggal di bantaran kanal.Tumpukan sampah pada Kanal Panampu terjadi disamping Pasar Terong dan Sungai Saddang Baru, karena pedagang Pasar terong yang berlokasi disekitar Kanal Panampu sebagian besar memanfaatkan kanal tersebut untuk membuang sampah sehingga terjadi pencemaran kanal. Hal ini juga dapat menyebabkan terjadinya banjir ketika curah hujan yang tinggi.

\section{METODE}

\subsection{Lokasi Penelitian}

Penelitian ini dilakukan di sekitar Kanal Pannampu Pasar Terong, Kelurahan Tompo Balang, Kecamatan Bontoala, Kota Makassar.
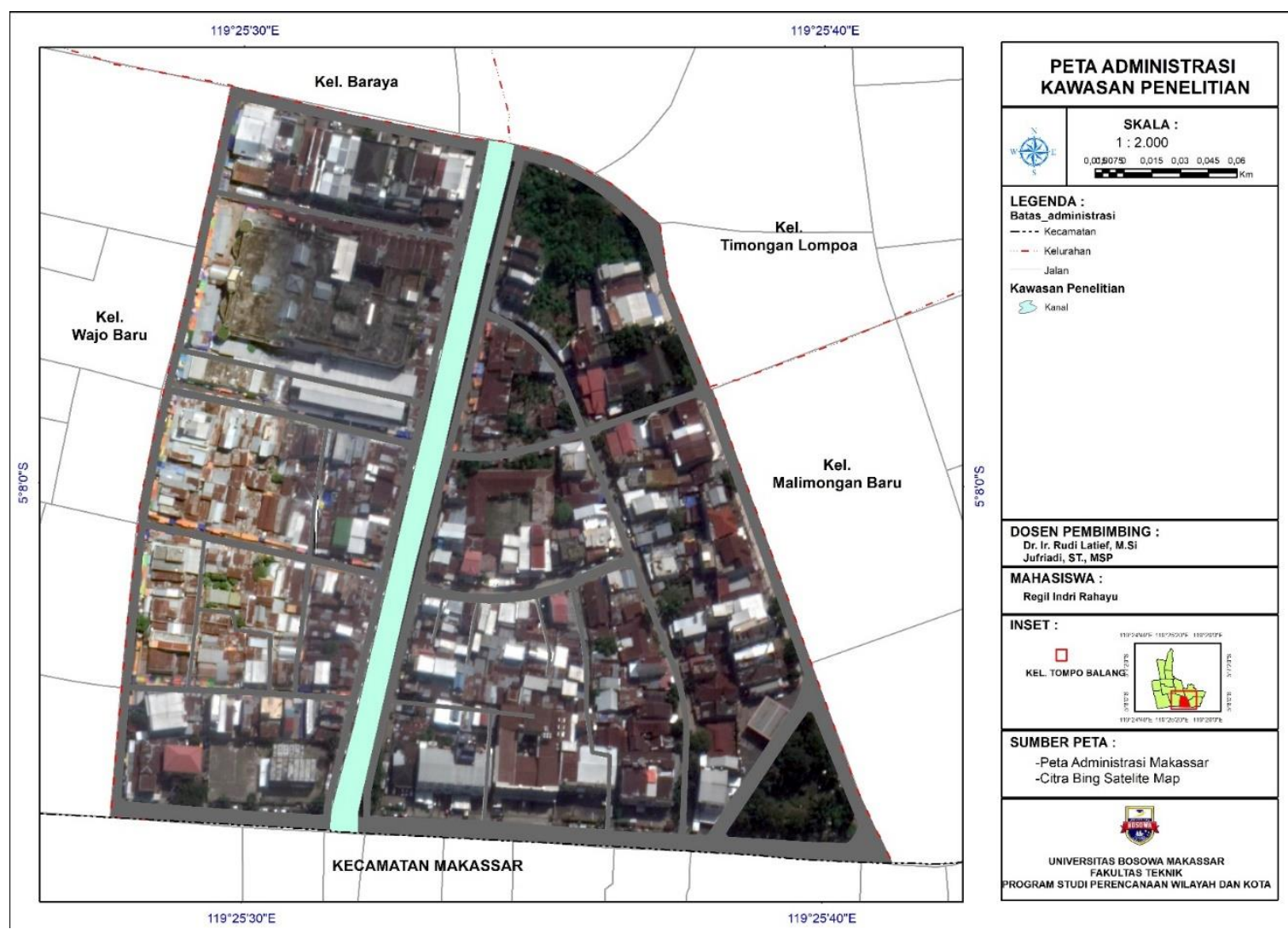

Gambar 1. Peta Lokasi Penelitian (Sumber: Pengolahan ArGIS, Tahun 2020)

\subsection{Populasi dan Sampel}

a. Populasi

Populasi adalah wilayah generalisasi yang terdiri atas objek yang mempunyai kualitas dan karakteristik tertentu yang ditetapkan oleh peneliti untuk dipelajari dan kemudian ditarik kesimpulannya. (Sugiyono, 2018). Dalam memecahkan masalah, langkah yang penting adalah menentukan populasi karena menjadi sumber data sekaligus sebagai objek penelitian. Populasi adalah sekumpulan objek yang menjadi pusat perhatian, yang padanya terkandung informasi yang ingin diketahui. Populasi dalam penelitian ini adalah pedagang Pasar Terong yang beraktifitas di pinggir Kanal Panampu.

\section{b. Sampel}

Sampel adalah bagian dari jumlah dan karakteristik yang dimiliki oleh populasi tersebut. Sehingga sampel merupakan bagian dari populasi yang ada, sehingga untuk pegambilan sampel harus menggunakan cara tertentu yang didasarkan oleh pertimbangan-pertimbangan yang ada. (Sugiyono, 2011:81).

\subsection{Teknik Pengambilan Data}

a. Metode Angket (Kuesioner)

Kuesioner adalah daftar pertanyaan yang dikirim kepada responden baik secara Iangsung maupun tidak Iangsung. Kuesioner atau angket secara umum dapat berbentuk pertanyaan atau pernyataan yang dapat dijawab 
sesuai bentuk angket. Apabila angket tertutup cara menjawab cukup dengan membubuhkan check list $(\sqrt{ })$ pada kolom. Sementara itu, apabila angket bersifat terbuka, cara menjawabnya dengan mengisi jawaban pada kolom yang tersedia.

b. Survei Lapangan

Teknik survei lapangan dilakukan untuk mendapatkan data yang lebih mendetail, aktual dan langsung untuk mendapatkan data primer dari objek penelitian. Data primer didapatkan dengan tinjauan langsung di lokasi penelitian dengan cara melakukan pengambilan data langsung di lapangan. Salah satu bentuk dan cara mendapatkan data primer berupa penyebaran kuesioner kepada masyarakat untuk data-data yang dibutuhkan dari lokasi penelitian untuk mendapatkan data secara detail, aktual dan langsung.

\subsection{Variabel Penelitian}

Variabel yang digunakan dalam penelitian ini adalah sebagai berikut :

Y : Perilaku Masyarakat

$\mathrm{X}_{1}$ : Pengetahuan Lingkungan

$\mathrm{X}_{2}$ : Pengetahuan Kebijakan Pemerintah

$\mathrm{X}_{3}$ : Pengetahuan Penerapan Teknologi

$\mathrm{X}_{4}$ : Sikap

$\mathrm{X}_{5}$ : Niat

\subsection{Metode Analisis Data}

Dalam penelitian ini menggunakan 2 Alat Analisis Data yaitu Analisis Chi Square dan Analisis SWOT.

a. Analisis Chi Square

Chi-Square adalah salah satu jenis uji komparatif non parametris yang dilakukan pada dua variabel, di mana skala data kedua variabel adalah nominal. (Apabila dari 2 variabel, ada 1 variabel dengan skala nominal maka dilakukan uji chi square dengan merujuk bahwa harus digunakan uji pada derajat yang terendah).

Analisis Chi-Square atau uji Chi-Square berguna untuk menguji pengaruh dua buah variabel nominal dan mengukur kuatnya hubungan antara variabel yang satu dengan variabel nominal lainnya $(\mathrm{C}=$ Coefisien of contingency). (Husaini \& Purnomo, 2008:227)

\section{b. Analisis SWOT}

Analisis SWOT adalah metode analisis perencanaan strategis yang digunakan untuk memonitor dan mengevaluasi lingkungan perusahaan baik lingkungan eksternal dan internal untuk suatu tujuan bisnis tertentu. SWOT merupakan akronimdari kata kekuatan (strengths), kelemahan (weaknesses), peluang (opportunities), dan ancaman (threats) dalam suatu proyek atau suatu spekulasi bisnis.

\section{HASIL DAN PEMBAHASAN}

\subsection{Lokasi Penelitian}

Kelurahan Tompo Balang merupakan salah satu kelurahan yang ada di Kota Makassar yang memiliki luas sebesar $0,11 \mathrm{~km} \mathrm{Km} 2$ yang terdiri dari $4 \mathrm{RW}$ dan $13 \mathrm{RT}$. Dengan batas-batas wilayah administratif yaitu, sebelah utara berbatasan dengan Kabupaten Maros, sebelah selatan berbatasan dengan Kabupaten Gowa dan Kabupaten Takalar, sebelah Timur berbatasan dengan Kabupaten Gowa dan Kabupaten Maros. Pada tahun 2019 Kelurahan Tompo Balang memiliki jumlah penduduk sebanyak 3.133 jiwa. Dimana laki-laki sebanyak 1.525 jiwa dan perempuan sebanyak 1.608 jiwa.

Lokasi penelitian kali ini mengambil lokasi disekitar Kanal Panampu Pasar Terong, Kelurahan Tompo Balang, Kecamatan Bontoala, Kota Makassar. Tepatnya di RW 1 dan RW 2 di Kelurahan Tompo Balang. Dengan total luas lokasi $5.78 \mathrm{Ha}$. Adapun pertimbangan peneliti dalam mengambil lokasi ini yakni dikarenakan kurangnya kesadaran masyarakat sekitar untuk menjaga kebersihan lingkungan.

Sebagian besar pedagang masih sering membuang sampah langsung ke kanal, perilaku masyarakat seperti ini yang mengakibatkan menurunnya kualitas lingkungan disekitar kanal. Padahal seperti yang diketahui bahwa Kota Makassar khususnya pada Kelurahan Tompo Balang Kecamatan Bontoala rentang terjadinya banjir ketika hujan deras turun dalam waktu yang lama. 

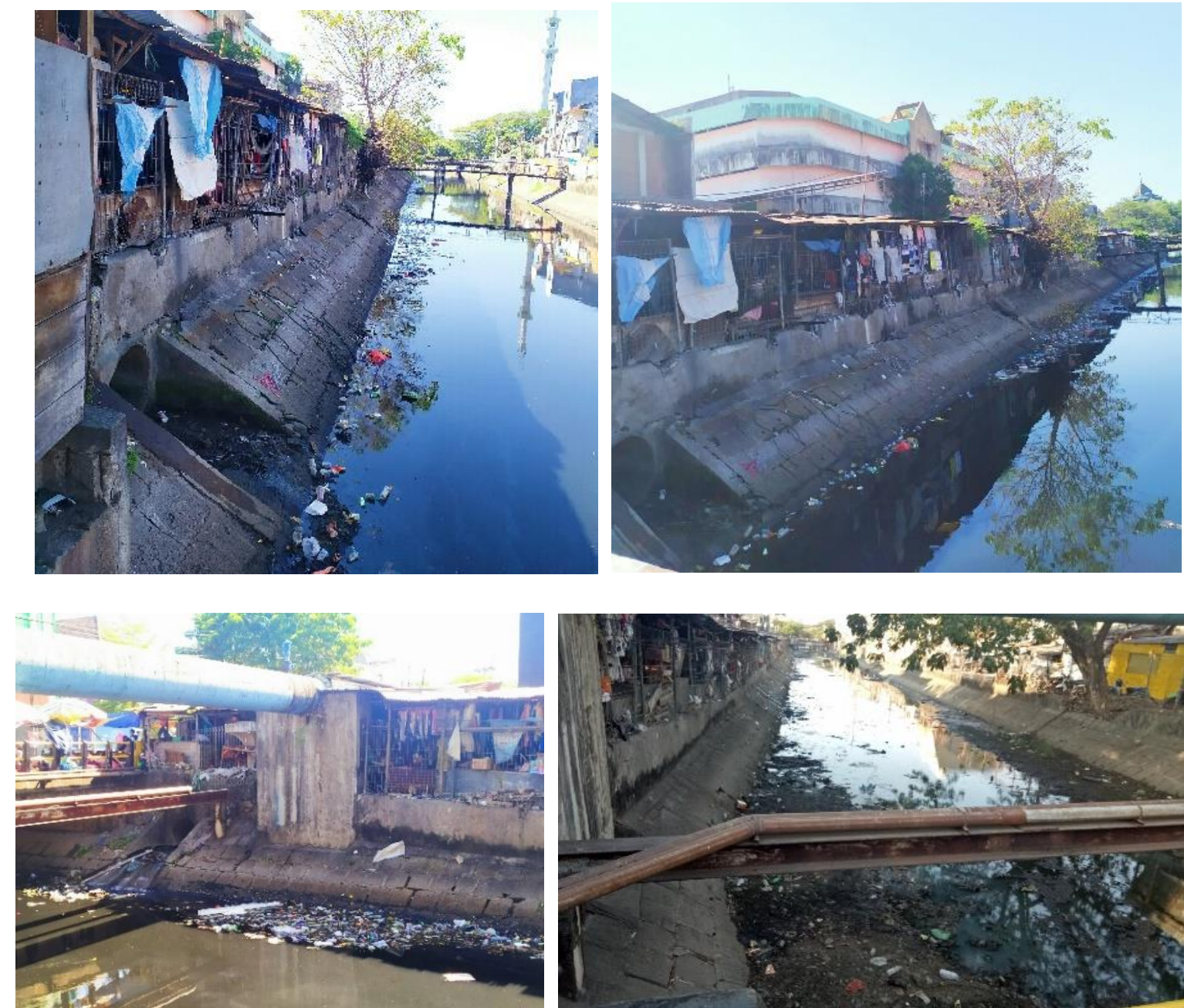

Gambar 2. Pencemaran terhadap Kanal Panampu Pasar Terong (Sumber : Hasil Survey Lapangan Tahun 2020)

\subsection{Analisis Chi-Square}

a. Pengaruh Pengetahuan Lingkungan terhadap Perilaku Masyarakat

Tabel 1. Analisis Pengaruh Pengetahuan Lingkungan $\left(\mathrm{X}_{1}\right)$ terhadap Perilaku Masyarakat (Y)

\begin{tabular}{|c|c|c|c|c|c|c|c|c|c|c|c|}
\hline & & $X$ & & $\sum$ & & $\mathrm{FH}$ & & & $\mathrm{K} 2$ & & $\sum$ \\
\hline $\mathrm{Y}$ & 1 & 2 & 3 & & 1 & 2 & 3 & 1 & 2 & 3 & \\
\hline 1 & 0 & 28 & 50 & 78 & 0 & 24,18 & 53,82 & 0 & 0,60 & 0,27 & 0,87 \\
\hline 2 & 0 & 1 & 19 & 20 & 0 & 6,2 & 13,8 & 0 & 4,36 & 1,96 & 6,32 \\
\hline 3 & 0 & 2 & 0 & 2 & 0 & 0,62 & 1,38 & 0 & 3,07 & 1,38 & 4,45 \\
\hline$\sum$ & 0 & 31 & 69 & 100 & & & & & & & \\
\hline $\mathrm{x}^{2}$ & & & & & & & & & & & 11,64 \\
\hline $\mathrm{Db}$ & & & & & & & $(3-1) \times(3-1)$ & & & & 4 \\
\hline $\mathrm{x}^{2}$ Tabel & & & & & & & & & & & 9,49 \\
\hline Kesimpulan & & & & & & & & & & & Ada Pengaruh \\
\hline
\end{tabular}

Sumber : Hasil Analisis Tahun 2020

Berdasarkan hasil analisis Chi Square menunjukkan bahwa Pengetahuan Lingkungan berpengaruh terhadap Perilaku Masyarakat. Untuk mengukur tingkat pengaruh Pengetahuan Lingkungan terhadap Perilaku Masyarakat, maka dilakukan uji kontingensi, dimana

$$
C: \sqrt{\frac{\mathrm{X}^{2}}{\left(\mathrm{~N}+\mathrm{X}^{2}\right)}} C: \sqrt{\frac{11,64}{(100+11,64)}}
$$

Diketahui bahwa hasil uji kontingensi adalah 0,32 atau Pengaruh Lemah. 
Regil Indri Rahayu ${ }^{1}$, Rudi Latief ${ }^{1}$, Jufriadi ${ }^{1} /$ Journal of Urban and Regional Spatial. Vol 01 No 02. Hal 165-173

b. Pengaruh Pengetahuan Kebijakan Pemerintah terhadap Perilaku Masyarakat

Tabel 2. Analisis Pengaruh Pengetahuan Kebijakan Pemerintah $\left(\mathrm{X}_{2}\right)$ terhadap Perilaku Masyarakat $(\mathrm{Y})$

\begin{tabular}{|c|c|c|c|c|c|c|c|c|c|c|c|}
\hline & & $\mathrm{X}$ & & $\sum$ & & FH & & & $\mathrm{x} 2$ & & $\sum$ \\
\hline $\mathrm{Y}$ & 1 & 2 & 3 & & 1 & 2 & 3 & 1 & 2 & 3 & \\
\hline 1 & 0 & 29 & 30 & 59 & 0 & 18,29 & 40,71 & 0 & 6,27 & 2,82 & 9,09 \\
\hline 2 & 0 & 1 & 23 & 24 & 0 & 7,44 & 16,56 & 0 & 5,57 & 2,50 & 8,07 \\
\hline 3 & 0 & 1 & 16 & 17 & 0 & 5,27 & 11,73 & 0 & 3,46 & 1,55 & 5,01 \\
\hline$\sum$ & 0 & 31 & 69 & 100 & & & & & & & \\
\hline$x^{2}$ & & & & & & & & & & & 22,17 \\
\hline $\mathrm{Db}$ & & & & & $(3-1)$ & & & & & & 4 \\
\hline $\mathrm{x}^{2}$ Tabel & & & & & & & & & & & 9,49 \\
\hline Kesimpulan & & & & & & & & & & & Ada Pengaruh \\
\hline
\end{tabular}

Berdasarkan hasil analisis Chi Square menunjukkan bahwa Pengetahuan Kebijakan Pemerintah berpengaruh terhadap Perilaku Masyarakat. Untuk mengukur tingkat pengaruh Pengetahuan Kebijakan Pemerintah terhadap Perilaku Masyarakat, maka dilakukan uji kontingensi, dimana

$$
C: \sqrt{\frac{\mathrm{X}^{2}}{\left(\mathrm{~N}+\mathrm{X}^{2}\right)}} C: \sqrt{\frac{22,17}{(100+22,17)}}
$$

Diketahui bahwa hasil uji kontingensi adalah 0,43 atau Pengaruh Sedang.

c. Pengaruh Pengetahuan Penerapan Teknologi terhadap Perilaku Masyarakat

Tabel 3. Analisis Pengaruh Pengetahuan Penerapan Teknologi $\left(\mathrm{X}_{3}\right)$ terhadap Perilaku Masyarakat $(\mathrm{Y})$

\begin{tabular}{|c|c|c|c|c|c|c|c|c|c|c|c|}
\hline & \multicolumn{3}{|c|}{$\mathrm{X}$} & $\sum$ & \multicolumn{3}{|c|}{$\mathrm{FH}$} & \multicolumn{3}{|c|}{$\mathrm{x} 2$} & \multirow[t]{2}{*}{$\sum$} \\
\hline $\mathrm{Y}$ & $1 / \mathrm{a}$ & $2 / b$ & $3 / \mathrm{c}$ & & 1 & 2 & 3 & 1 & 2 & 3 & \\
\hline $1 / \mathrm{a}$ & 0 & 29 & 3 & 32 & 0 & 9,92 & 22,08 & 0 & 36,70 & 16,49 & 53,19 \\
\hline $2 / \mathrm{b}$ & 0 & 1 & 36 & 37 & 0 & 11,47 & 25,53 & 0 & 9,56 & 4,29 & 13,85 \\
\hline $3 / \mathrm{c}$ & 0 & 1 & 30 & 31 & 0 & 9,61 & 21,39 & 0 & 7,71 & 3,47 & 11,18 \\
\hline$\sum$ & 0 & 31 & 69 & 100 & & & & & & & \\
\hline$x^{2}$ & & & & & & & & & & & 78,22 \\
\hline $\mathrm{Db}$ & & & & & $(3-$ & 3-1) & & & & & 4 \\
\hline $\mathrm{x}^{2}$ Tabel & & & & & & & & & & & 9.49 \\
\hline
\end{tabular}

Sumber : Hasil Analisis Tahun 2020

Berdasarkan hasil analisis Chi Square menunjukkan bahwa Pengetahuan Penerapan Teknologi berpengaruh terhadap Perilaku Masyarakat. Untuk mengukur tingkat pengaruh Pengetahuan Penerapan Teknologi terhadap Perilaku Masyarakat, maka dilakukan uji kontingensi, dimana

$$
C: \sqrt{\frac{\mathrm{X}^{2}}{\left(\mathrm{~N}+\mathrm{X}^{2}\right)}} C: \sqrt{\frac{78,22}{(100+75,55)}}
$$

Diketahui bahwa hasil uji kontingensi adalah 0,67 atau Pengaruh Kuat.

d. Pengaruh Sikap Terhadap Perilaku Masyarakat

\begin{tabular}{|c|c|c|c|c|c|c|c|c|c|c|c|}
\hline & \multicolumn{3}{|c|}{$X$} & \multirow[t]{2}{*}{$\sum$} & \multicolumn{3}{|c|}{$\mathrm{FH}$} & \multicolumn{3}{|c|}{$\mathrm{x} 2$} & \multirow[t]{2}{*}{$\sum$} \\
\hline $\mathrm{Y}$ & $1 / \mathrm{a}$ & $2 / \mathrm{b}$ & $3 / \mathrm{c}$ & & 1 & 2 & 3 & 1 & 2 & 3 & \\
\hline $1 / \mathrm{a}$ & 0 & 30 & 69 & 99 & 0 & 30,69 & 68,31 & 0 & 0,02 & 0,01 & 0,03 \\
\hline $2 / \mathrm{b}$ & 0 & 1 & 0 & 1 & 0 & 0,31 & 0,69 & 0 & 1,54 & 0,69 & 2,23 \\
\hline $3 / \mathrm{c}$ & 0 & 0 & 0 & 0 & 0 & 0 & 0 & 0 & 0 & 0 & 0 \\
\hline$\sum$ & 0 & 31 & 69 & 100 & & & & & & & \\
\hline$x^{2}$ & & & & & & & & & & & 2,26 \\
\hline $\mathrm{Db}$ & & & & & (3-1) & -1) & & & & & 4 \\
\hline $\mathrm{x}^{2}$ Tabel & & & & & & & & & & & 9,49 \\
\hline Kesimpulan & & & & & & & & & & & $\begin{array}{c}\text { Tidak } \\
\text { Ada } \\
\text { Pengaruh }\end{array}$ \\
\hline
\end{tabular}

Tabel 4. Analisis Pengaruh Sikap $\left(\mathrm{X}_{4}\right)$ terhadap Perilaku Masyarakat (Y) 
Berdasarkan hasil analisis Chi Square menunjukkan bahwa Sikap tidak berpengaruh terhadap Perilaku Masyarakat. Untuk mengukur tingkat pengaruh Sikap terhadap Perilaku Masyarakat, maka dilakukan uji kontingensi, dimana

$$
C: \sqrt{\frac{\mathrm{X}^{2}}{\left(\mathrm{~N}+\mathrm{X}^{2}\right)}} C: \sqrt{\frac{2,26}{(100+2,26)}}
$$

Diketahui bahwa hasil uji kontingensi adalah 0,15 atau Pengaruh Sangat Lemah.

e. Pengaruh Niat terhadap Perilaku Masyarakat

Tabel 5. Analisis Pengaruh Niat $\left(\mathrm{X}_{5}\right)$ terhadap Perilaku Masyarakat (Y)

\begin{tabular}{|c|c|c|c|c|c|c|c|c|c|c|c|}
\hline & \multicolumn{3}{|c|}{$\mathrm{X}$} & $\sum$ & \multicolumn{3}{|c|}{$\mathrm{FH}$} & \multicolumn{3}{|c|}{$\mathrm{x} 2$} & \multirow[t]{2}{*}{$\sum$} \\
\hline Y & $1 / \mathrm{a}$ & $2 / \mathrm{b}$ & $3 / \mathrm{c}$ & & 1 & 2 & 3 & 1 & 2 & 3 & \\
\hline $1 / \mathrm{a}$ & 0 & 29 & 14 & 43 & 0 & 13,33 & 29,67 & 0 & 18,42 & 8,28 & 26,7 \\
\hline $2 / \mathrm{b}$ & 0 & 1 & 40 & 41 & 0 & 12,71 & 28,29 & 0 & 10,79 & 4,85 & 15,64 \\
\hline $3 / \mathrm{c}$ & 0 & 1 & 15 & 16 & 0 & 4,96 & 11,04 & 0 & 3,16 & 1,42 & 4,58 \\
\hline$\sum$ & 0 & 31 & 69 & 100 & & & & & & & \\
\hline$x^{2}$ & & & & & & & & & & & 46,92 \\
\hline $\mathrm{db}$ & & & & & $3-1)$ & & & & & & 4 \\
\hline $\mathrm{x}^{2}$ Tabel & & & & & & & & & & & 9,49 \\
\hline Kesimpulan & & & & & & & & & & & Ada Pengaruh \\
\hline
\end{tabular}

Sumber : Hasil Analisis Tahun 2020

Berdasarkan hasil analisis Chi Square menunjukkan bahwa Niat berpengaruh terhadap Perilaku Masyarakat. Untuk mengukur tingkat pengaruh Niat terhadap Perilaku Masyarakat, maka dilakukan uji kontingensi, dimana

$$
C: \sqrt{\frac{\mathrm{X}^{2}}{\left(\mathrm{~N}+\mathrm{X}^{2}\right)}} C: \sqrt{\frac{46,92}{(100+46,92)}}
$$

Diketahui bahwa hasil uji kontingensi adalah 0,57 atau Pengaruh Sedang.

\begin{tabular}{|c|c|c|c|c|c|}
\hline No & Variabel & Pengaruh & $X^{2}$ & $\begin{array}{c}\text { Uji } \\
\text { Kontingensi }\end{array}$ & Kesimpulan \\
\hline 1. & Pengetahuan Lingkungan $\left(\mathrm{X}_{1}\right)$ & Ada Pengaruh & $\begin{array}{c}11,6 \\
4\end{array}$ & 0,32 & Pengaruh Lemah \\
\hline 2. & $\begin{array}{c}\text { Pengetahuan Kebijakan } \\
\text { Pemerintah }\left(\mathrm{X}_{2}\right)\end{array}$ & Ada Pengaruh & $\begin{array}{c}22,1 \\
7\end{array}$ & 0,43 & Pengaruh Sedang \\
\hline 3. & $\begin{array}{c}\text { Pengetahuan Penerapan } \\
\text { Teknologi }\left(\mathrm{X}_{3}\right)\end{array}$ & Ada Pengaruh & $\begin{array}{c}75,5 \\
5\end{array}$ & 0,66 & Pengaruh Kuat \\
\hline 4. & Sikap $\left(\mathrm{X}_{4}\right)$ & $\begin{array}{l}\text { Tidak ada } \\
\text { Pengaruh }\end{array}$ & 2,26 & 0,15 & $\begin{array}{c}\text { Pengaruh Sangat } \\
\text { Lemah }\end{array}$ \\
\hline 5. & Niat $\left(X_{5}\right)$ & Ada Pengaruh & $\begin{array}{c}46,9 \\
2\end{array}$ & 0,57 & Pengaruh Sedang \\
\hline
\end{tabular}

Tabel 6. Rangkuman Analisis Chi-Square antara variabel X dan Y

Sumber : Hasil Analisis Tahun 2020

\subsection{Analisis SWOT}

a. Internal Strategy Factor Analysis (IFAS)

\begin{tabular}{|c|c|c|c|c|c|}
\hline No & Kekuatan & $\mathrm{SP}$ & $\mathrm{K}$ & $\mathrm{Sp} \times \mathrm{K}$ & Bobot \\
\hline 1. & Pengetahuan Lingkungan & 12 & 4 & 48 & 0,2 \\
\hline 2. & Pengetahuan Kebijakan Pemerintah & 16 & 4 & 64 & 0,27 \\
\hline 3. & Pengetahuan Penerapan Teknologi & 16 & 4 & 64 & 0,27 \\
\hline 4. & Niat & 16 & 4 & 64 & 0,27 \\
\hline & Jumlah & & & 240 & 1,01 \\
\hline No. & Kelemahan & SP & $\mathrm{K}$ & $\mathrm{Sp} \times \mathrm{K}$ & Bobot \\
\hline 1. & Sikap & 16 & 4 & 64 & 1 \\
\hline & Jumlah & & & 64 & 1 \\
\hline
\end{tabular}

Tabel 7. Matriks Internal Strategy Factor Analysis (IFAS) 
Tabel 8. Matriks Nilai Skor Internal Strategy Factor Analysis (IFAS)

\begin{tabular}{clcccc}
\hline No & & Kekuatan & Bobot & Rating (1-4) & Skor \\
\hline 1. & Pengetahuan Lingkungan & 0,2 & 3 & 0,6 \\
\hline 2. & Pengetahuan Kebijakan Pemerintah & 0,27 & 4 & 1,08 \\
\hline 3. & Pengetahuan Penerapan Teknologi & 0,27 & 4 & 1,08 \\
\hline 4. & Niat & Jumlah & 0,27 & 4 & 1,08 \\
\hline & & 1,01 & & 3,84 \\
\hline No & & Bobot & Rating (4-1) & Skor \\
\hline 1. & Sikap & Jumlah & 1 & 3 & 3 \\
\hline & & 1 & & 3 \\
\hline
\end{tabular}

Sumber : Hasil Analisis Tahun 2020

Berdasarkan tabel di atas dapat disimpulkan bahwa nilai skor internal faktor yaitu Kekuatan sebesar 3,84 dan Kelemahan sebesar 3 dengan kata lain bahwa kedua faktor internal ini merupakan faktor yang sangat Kuat.

b. Eksternal Strategy Factor Analysis (EFAS)

Tabel 9. Matriks Eksternal Strategy Factor Analysis (EFAS)

\begin{tabular}{|c|c|c|c|c|}
\hline No & Peluang & SP $\mathrm{K}$ & Sp x K & Bobot \\
\hline 1. & $\begin{array}{l}\text { Berdasarkan RTRW Kota Makassar 2015-2035, objek penelitian atau } \\
\text { Kelurahan Tompo Balang termasuk dalam kawasan rawan banjir }\end{array}$ & 16 & 64 & 0,36 \\
\hline 2. & $\begin{array}{l}\text { Undang-Undang Republik Indonesia Nomor } 1 \text { Tahun } 2011 \text { tentang } \\
\text { Pengelolaan Sampah }\end{array}$ & 16 & 64 & 0,36 \\
\hline \multirow[t]{2}{*}{3.} & $\begin{array}{l}\text { Permen PU Nomor } 12 \text { tentang Penyelengaraan Sistem Drainase } \\
\text { Perkotaan }\end{array}$ & 12 & 48 & 0,27 \\
\hline & Jumlah & & 176 & 0,99 \\
\hline No & Ancaman & SP $\quad \mathrm{K}$ & Sp x K & Bobot \\
\hline 1. & Kurangnya Fasilitas Persampahan & 16 & 64 & 0,5 \\
\hline \multirow[t]{2}{*}{2.} & Kurangnya Kesadaran Masyarakat dalam Menjaga Kebersihan Kanal & 16 & 64 & 0,5 \\
\hline & Jumlah & & 128 & 1 \\
\hline \multicolumn{5}{|c|}{ Sumber: Hasil Analisis Tahun 2020} \\
\hline \multicolumn{5}{|c|}{ Tabel 10. Matriks Eksternal Strategy Factor Analysis (EFAS) } \\
\hline No. & Peluang & Bobot & $\begin{array}{c}\text { Rating } \\
(1-4)\end{array}$ & Skor \\
\hline 1 & $\begin{array}{l}\text { Berdasarkan RTRW Kota Makassar 2015-2035, objek penelitian atau } \\
\text { Kelurahan Tompo Balang termasuk dalam kawasan rawan banjir }\end{array}$ & 0,36 & 4 & 1,44 \\
\hline 2 & $\begin{array}{l}\text { Undang-Undang Republik Indonesia Nomor } 1 \text { Tahun } 2011 \text { tentang } \\
\text { Pengelolaan Sampah }\end{array}$ & 0,36 & 4 & 1,44 \\
\hline \multirow[t]{2}{*}{3} & $\begin{array}{l}\text { Permen PU Nomor } 12 \text { tentang Penyelengaraan Sistem Drainase } \\
\text { Perkotaan }\end{array}$ & 0,27 & 3 & 0,81 \\
\hline & Jumlah & 0,99 & & 3,69 \\
\hline No. & Ancaman & Bobot & $\begin{array}{c}\text { Rating } \\
(4-1)\end{array}$ & Skor \\
\hline 1. & Kurangnya Fasilitas Persampahan & 0,5 & 1 & 0,5 \\
\hline \multirow[t]{2}{*}{2.} & Kurangnya Kesadaran Masyarakat dalam Menjaga Kebersihan Kanal & 0,5 & 1 & 0,5 \\
\hline & Jumlah & 1 & & 1 \\
\hline
\end{tabular}

Sumber : Hasil Analisis Tahun 2020

Berdasarkan tabel di atas dapat disimpulkan bahwa nilai skor eksternal faktor yaitu Peluang sebesar 3,69 dan Ancaman sebesar 1 dengan kata lain bahwa kedua faktor eksternal ini merupakan faktor yang sangat Kuat

Analisis matriks Intenal dan Eksternal digunakan untuk mencari strategi umum (Grand strategi) atau strategi apa yang sebaliknya digunakan. Penentuan strategi ini diperoleh dari hasil perhitungan matriks IFAS dan EFAS, dimana nilai dari indeks akumulatif skor IFAS kekuatan sebesar 3,84 sedangkan nilai akhir bobot skor elemen 
kelemahan sebesar 3. Sedangkan hasil perhitungan matriks EFAS peluang sebesar 3,69 sedangkan nilai akhir bobot skor elemen ancaman sebesar 1 menunjukkan besarnya pengaruh ektsernal.

Selanjutnya untuk melihat strategi dominan yang akan digunakan maka hasil dari IFAS dan EFAS dijadikan sebagai titik penentu koordinat X dan Y, dimana IFAS sebagai X (kekutan-kelemahan) dan EFAS sebagai Y (peluang-ancaman). Untuk lebih jelasnya bisa kita lihat pada gambar 3. berikut ini :

- (IFAS) Hasil Kekuatan - Kelemahan : 3,84- $3 \quad=0,84$

- (EFAS) Hasil Peluang - Ancaman : : 3,69-1 = 2,69

Stability (Stabil) O (OPPURTUNITY) Growth (Pertumbuhan)

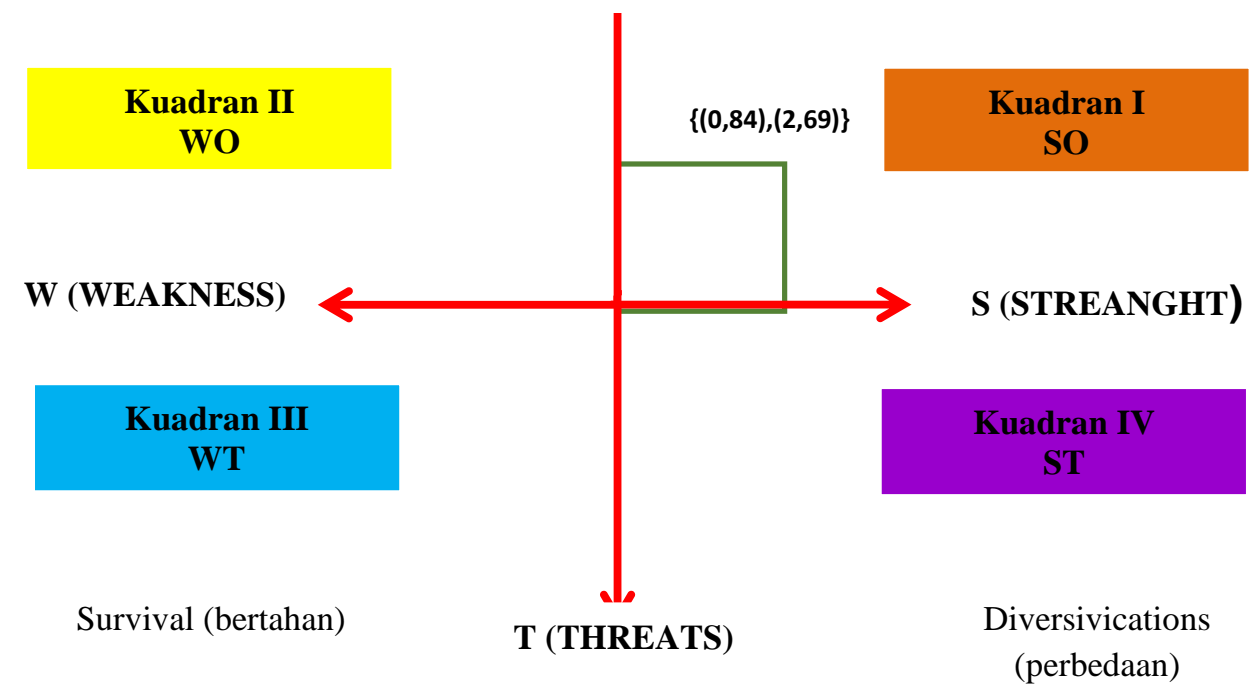

Gambar 3. Kuadran Hasil Analisis SWOT

Posisi berada pada sumbu $X=0,84$ dan sumbu $Y=2,69$ jadi posisi kuadran berada pada kuadran I dengan strategi yang digunakan dan diprioritaskan yaitu Strategi S0 (Rumusan strategi dalam memanfaatkan kekuatan yang ada untuk meraih peluang).

Berdasarkan dari hasil analisis SWOT untuk merumuskan strategi Aktifitas Pedagang yang Berlokasi di Sekitar Kanal Panampu Pasar Terong Terhadap Pencemaran Kanal dengan hasil perhitungan kuadran, maka rumusan strategi berada pada kuadran I yaitu Strategi S0, artinya bahwa terdapatnya Kekuatan (S) dalam meraih peluang (O).Alternatif strategi dalam peningkatan partisipasi masyarakat dirumuskan dengan pendekatan analisis SWOT. Analisis matriks SWOT merupakan langkah selanjutnya setelah dilakukan analisis IFAS dan EFAS, yakni dengan mencocokan faktor-faktor internal berupa kekuatan dan kelemahan dengan faktor-faktor eksternal berupa peluang dan ancaman yang mempengaruhi peningkatan perilaku masyarakat terhadap pencemaran Kanal Panampu.Untuk lebih jelasnya matriks SWOT dalam perumusan strategi Aktifitas Pedagang yang Berlokasi di Sekitar Kanal Panampu Pasar Terong Terhadap Pencemaran Kanal dapat dilihat pada tabel 11 sebagai berikut.

Tabel 11. Matriks SWOT Strategi Aktifitas Pedagang Terhadap Pencemaran Kanal yang Berlokasi di Sekitar Kanal Panampu Pasar Terong Kota Makassar

\begin{tabular}{|c|c|c|}
\hline \multirow[b]{2}{*}{ Eksternal } & Kekuatan (S) & Kelemahan (W) \\
\hline & $\begin{array}{ll}\text { 1. Pengetahuan Lingkungan } \\
\text { 2. Pengetahuan Kebijakan } \\
\text { Pemerintah } \\
\text { 3. Pengetahuan Penerapan } \\
\text { Teknologi } \\
\text { 4. Niat }\end{array}$ & 1. Sikap (Perilaku Masyarakat) \\
\hline Peluang (O) & $\begin{array}{c}\text { Strategi S-O } \\
\text { (Aggresive Strategies) }\end{array}$ & $\begin{array}{c}\text { Strategi W-O } \\
\text { (Turn Arround Strategies) }\end{array}$ \\
\hline
\end{tabular}


1. Berdasarkan RTRW Kota Makassar 2015-2035, objek penelitian atau Kelurahan Tompo Balang termasuk dalam kawasan rawan banjir

2. Undang-Undang Republik Indonesia Nomor 1 Tahun 2011 tentang Pengelolaan Sampah

3. Permen PU Nomor 12 tentang Penyelenggaraan Sistem Drainase Perkotaan

1. Mensosialisasikan kepada masyarakat terkait RTRW Kota Makassar dalam hal kawasan rawan banjir, sehingga Pengetahuan dan Niat Masyarakat lebih meningkat dalam menjaga kebersihan Kanal.

2. Memanfaatkan Kebijakan terkait Pengelolaan Sampah dan Penyelenggaraan Sistem Drainase Perkotaan, sehingga Perilaku Masyarakat akan lebih memperhatikan kebersihan kanal.

3. Memanfaatkan teknologi dalam mengelola sampah dan memperbaiki sistem dranase

\begin{tabular}{|c|c|c|}
\hline Ancaman (T) & $\begin{array}{c}\text { Strategi S-T } \\
\text { (Divensification Strategies) }\end{array}$ & $\begin{array}{c}\text { Strategi W-T } \\
\text { (Defensive Strategies) }\end{array}$ \\
\hline $\begin{array}{ll}\text { 1. } & \text { Kurangnya Fasilitas Persampahan } \\
\text { 2. } & \text { Kurangnya Kesadaran Masyarakat } \\
\text { dalam Menjaga Kebersihan Kanal }\end{array}$ & 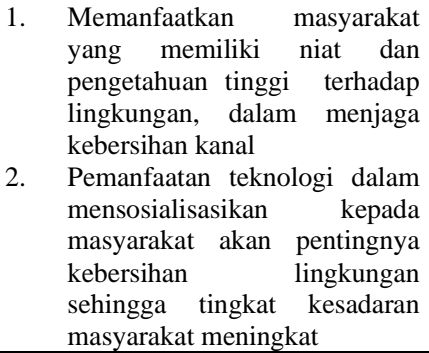 & $\begin{array}{l}\text { 1. Mengoptimalkan fasilitas persampahan } \\
\text { agar pedagang pasar terong ataupun } \\
\text { masyarakat yang bermukim di sekitar } \\
\text { Kanal Panampu, tidak lagi membuang } \\
\text { sampah ke kanal } \\
\text { 3. Memanfaatkan masyarakat yang memiliki } \\
\text { sikap peduli terhadap lingkungan, dalam } \\
\text { menjaga kebersihan kanal }\end{array}$ \\
\hline
\end{tabular}

Berdasarkan tabel di atas maka dapat disimpulkan bahwa strategi SO yang di gunakan dalam Penelitian ini. memanfaatkan Kekuatan yang ada untuk meraih Peluang. Sehingga kebersihan kanal tetap terjaga. Berikut Strategi SO dalam Penelitian ini yaitu Mensosialisasikan kepada masyarakat terkait RTRW Kota Makassar dalam hal kawasan rawan banjir, sehingga Pengetahuan dan Niat masyarakat lebih meningkat dalam menjaga kebersihan Kanal dan Memanfaatkan Kebijakan terkait Pengelolaan Sampah dan Penyelenggaraan Sistem Drainase Perkotaan, sehingga Perilaku Masyarakat akan lebih memperhatikan Kebersihan Kanal, serta memanfaatkan teknologi dalam mengelola sampah dan memperbaiki sistem drainase.

\section{KESIMPULAN}

Penyebab terjadinya Pencemaran Kanal di Kanal Panampu Pasar Terong Kota Makassar yaitu kurangnya tingkat Pengetahuan Lingkungan, Pengetahuan Kebijakan Pemerintah, Pengetahuan Penerapan Teknologi dan Niat, sehingga mempengaruhi Perilaku Masyarakat. Arahan Strategi Aktifitas Pedagang terhadap Pencemaran Kanal yang Berlokasi di Sekitar Kanal Panampu Pasar Terong Kota Makassar, yaitu Mensosialisasikan kepada masyarakat terkait RTRW Kota Makassar dalam hal kawasan rawan banjir, sehingga Pengetahuan dan Niat masyarakat lebih meningkat dalam menjaga kebersihan Kanal, Memanfaatkan kebijakan terkait Pengelolaan Sampah dan Penyelenggaraan Sistem Drainase Perkotaan, sehingga Perilaku Masyarakat akan lebih memperhatikan Kebersihan Kanal, serta Memanfaatkan teknologi dalam mengelola sampah dan memperbaiki sistem drainase.

\section{DAFTAR PUSTAKA}

Sugiyono., (2018). Metode Penelitian Kualitatif. Bandung: Alfabeta

Sugiyono., (2011). Metode Penelitian Kuantitatif, Kualitatif, dan R\&B. Bandung: Alfabeta

Sujatmiko., (2014). Kamus IPS. Surakarta: Aksara Sinergi Media

Usman, Husaini \& Purnomo., (2008). Metodologi Penelitian Sosial. Jakarta: PT Bumi Aksara

Pelajaran. Pengertian Pencemaran Lingkungan : Penyebab, Jenis, Dampak dan Cara Mengatasinya. Tersedia di https://www.pelajaran.co.id/2020/02/pencemaran-

lingkungan.html\#: :text=Pengertian\%20pencemaran20lingkungan\%20menurut\%20R.T.M,yang\%20berbah aya\%20terhadap\%20lingkungan\%20itu diakses pada 18 Agustus 2020

Syviana Toemon. Mengenal Kanal, Saluran Air Buatan Manusia. Tersedia di https://bobo.grid.id/read/08675248/mengenal-kanal-saluran-air-buatan-manusia?page=all diakses pada 20 Agustus 2020

Wikipedia. Analisis SWOT. Tersedia di https://id.wikipedia.org/wiki/Analisis_SWOT diakses pada 24 Agustus 2020

Dosen Sosiologi. Pengertian Kuesioner, Jenis, dan Contohnya Lengkap. Tersedia di https://dosensosiologi.com/pengertian-kuesioner-jenis-dan-contohnya-lengkap/ 